\title{
CUTTING WASTE BY MAKING RULES: \\ PROMISES, PITFALLS, AND REALISTIC PROSPECTS
}

\section{JAN BLUSTEIN \& THEODORE R. MARMOR†}

American medical costs, one hardly needs to say, continue to rise relentlessly. In 1990, health expenditures consumed approximately $12.2 \%$ of America's GNP. ${ }^{1}$ A decade earlier, the share was 9.1\%. ${ }^{2}$ In 1970 , we spent approximately $7.4 \% .^{3}$ There has developed an apparent consensus-among government, labor, and profession leaders-that costs must be contained. At the same time, there is widespread agreement that access must be universalized. As a result, many believe that excruciatingly hard choices are unavoidable.

This perceived dilemma has led to a great deal of talk about rationing. ${ }^{4}$ The tenor of the commentary indicates that it is a

† Dr. Jan Blustein is a physician and a fellow in health policy at New York University's Robert F. Wagner School. Professor Theodore Marmor teaches politics, policy, and law at Yale University's School of Organization and Management. Dr. Blustein was supported by an NRSA Award from the Agency for Health Care Policy and Research; Prof. Marmor received support from the Canadian Institute for Advanced Research, of which he is a fellow. The authors wish to thank David Willis, Philip Lee, Victor Rodwin, and Colin Dayan for their helpful comments on previous drafts. The usual caveats apply.

I See Katharine R. Levit et al., National Health Expenditures, 1990, HEALTH CARE FINANCING REV., Fall 1991, at 29, 30.

${ }^{2}$ See BUREAU OF CENSUS, U.S. DEP'T OF COMMERCE, STATISTICAL ABSTRACT OF THE UNITED STATES 1990, at 92 (110th ed. 1990).

${ }^{3}$ See id.

4 The topic of rationing first drew widespread attention with the publication of Aaron and Schwartz's pioneering comparative study of the scale and distribution of therapeutic procedures under Britain's National Health Service and America's health care system. See HenRY J. Aaron and William B. Schwartz, The Painful PRESCRIPTION: RATIONING HOSPITAL CARE (1984). Their argument, that British-style rationing decisions will inevitably need to be made in this country, has subsequently been elaborated upon. See William B. Schwartz, The Inevitable Failure of Current CostContainment Strategies: Why They Can Parade Only Temporary Relief, 257 JAMA 220 (1987). For a critical analysis, see Theodore Marmor \&c Rudolf Klein, Costs Versus Care: America's Health Care Dilemma Wrongly Considered, 4 HEALTH MATRIX 19 (1986).

A second wave of popular attention to rationing accompanied Oregon's controversial and widely noted proposal to alter the list of reimbursable services under the Medicaid program. For an evenhanded description of that program, under which reimbursement decisions would be guided by "cost-effectiveness" considerations, see Daniel M. Fox and Howard M. Leichter, Rationing Health Care in Oregon: The New Accountability, HEALTH AFF., Summer 1991, at 7; for an illuminating discussion of the politics surrounding the plan, see Lawrence D. Brown, The National Politics of Oregon's Rationing Plan, HEALTH AFF., Summer 1991, at 28; for an analysis 
fearsome solution to our present troubles-painful and divisive, entailing choices that no one wants to make but which must be faced due to inescapable scarcity. ${ }^{5}$ Both contemporary rhetoric and current health policy, however, hold out the hope of a far more agreeable alternative. Galvanized by the realization that much medical care is of uncertain value, and bolstered by findings that show significant variation in medical practice patterns, a coalition of policymakers, politicians, and researchers is now actively engaged in seeking to contain costs by eliminating wasteful care. This appears an attractive course. Waste-cutting, unlike rationing, does not connote the cruel denial of necessary care. On the contrary, it suggests saving people from medical interventions that would not have done them any good. If "rationing" is the fearsome alternative, "cutting waste" is the benign one.

While consensus grows that wasteful practice is a problem, there is considerable disagreement about the solution. Such disagreement is hardly surprising, since cutting waste is merely a goal, not a program. Cutting waste can mean any of a number of things. It can mean regionalizing services, instituting yearly expenditure targets, implementing managed care systems, or developing elaborate review mechanisms to constrain the diffusion of new technologies. Indeed, the idea of "cutting waste" is so broad in its potential scope that it can subsume many hotly debated reforms in the field of health policy. Like Health Maintenance Organizations, competition, and Diagnostic Related Groups before it, it is another vaunted panacea, the new great answer to arrive on the American health policy agenda. ${ }^{6}$

of the ethical issues it raises, see Norman Daniels, Is The Oregon Rationing Plan Fair?, 265 JAMA 2232 (1991); and for a particularly critical review of the plan as an effort to limit services to the poor, see Bruce C. Vladeck, Unhealthy Rations, AM. PROSPECT, Summer 1991, at 101.

${ }^{5}$ See Theodore R. Marmor \& Jan Blustein, Introduction to Rationing, 140 U. PA. L. REv. 1539 (1992).

${ }^{6}$ A reader of the popular press might well conclude that one-quarter to one-half of present medical practice is "pure waste," benefitting no one. For example, according to a New York Times op-ed piece of a few years ago:

[T] he evidence is now overwhelming that at least twenty-five percent of the money that Americans spend on health care is wasted.... There is a growing consensus that half the coronary bypasses, most Caesarean sections and a significant proportion of many other procedures . . . are unnecessary. A former editor of [JAMA] is convinced that more than half of the 40 million medical tests performed each year "do not really contribute to a patient's diagnosis or therapy."

Joseph A. Califano, Jr., Billions Blown on Health, N.Y. TIMES, Apr. 12, 1989, at A25. 
This essay critically assesses the widely advertised plan to cut waste by making microallocational rules for the provision of medical care. Such rules, variously denominated "practice parameters," "clinical guidelines," and "standards of care," are aimed at ensuring that no patient is subjected to "wasteful" care by specifying what treatments particular patients should receive. For example, the rule that "healthy patients under 40 years of age without a family history of heart disease should not be given an electrocardiogram" is a practice parameter. It could be used by physicians to guide day-to-day treatment decisions. It could also be used by payers to control reimbursement, and by policymakers to appraise aggregate data about medical care utilization. ${ }^{10}$

Our analysis raises the fundamental but too-little discussed question of what constitutes waste. Our central claim is that socalled "wasteful" practice is a conceptual hodgepodge, which encompasses treatments that are (1) ineffective; (2) of uncertain effectiveness; (3) ethically troubling; or (4) not allocationally efficient. ${ }^{11}$ From this starting point, we address issues of rule making and resource allocation and ask the following questions: Can all four of these types of wasteful care be identified in ways that are scientifically defensible and administratively practicable? What obstacles must be faced to make cutting waste by making rules into a policy in each case? Are there American institutions and attitudes that would make such rule making more costly, and therefore less attractive, than it seems? And can any (or all) of these four types of

${ }^{7}$ See James S. Todd, M.D.: Only Parameters Will Give MDs Needed Flexibility, AM. MED. NEws, Jan. 6, 1989, at 23, 23 [hereinafter, Todd Interview] (interview with AMA Senior Deputy Executive Vice President).

${ }^{8}$ See Agency for Health Gare Policy and Research, U.S. DEP'T Of Health and Human Servs., Program Note: Clinical Guideline Development (1990) [hereinafter AHCPR, PROGRAM NOTE].

${ }^{9}$ See Mark R. Chassin, Standards of Care in Medicine, 25 INQUIRY 437, 437 (1988).

${ }^{10}$ This Article does not address recently developed techniques, such as "physician profiling," whereby payors examine physicians' patterns of care in order to detect tendencies toward inappropriate or wasteful use of services. See Robert W. Dubois, Reducing Unnecessary Care: Different Approaches to the "Big Ticket" and the "Little Ticket" Items, J. AMBULATORY CARE MGMT., October 1991, at 30; Milt Freudenheim, Software Controls on Health Costs, N.Y. Times, Feb. 18, 1992, at D2. Many of our comments apply equally well to these newer approaches, however.

11 Those falling into this last category are often said to be "not cost-effective," but this term is all too often used imprecisely. In the medical literature "cost-effective" has been variously taken to be synonymous with "cost saving," "effective," and "having an additional benefit worth the cost." See Peter Doubilet et al., Use and Misuse of the Term 'Cost-Effective' in Medicine, 314 NEW ENG. J. MED. 253, 253-54 (1986). 
waste be cut without confronting the dilemma of difficult choices? But before approaching these questions, we begin by briefly reviewing the ways in which the problem of wasteful care has been framed by health care analysts, providers, and policymakers.

\section{LoOse TAlK ABout "WASTE."}

Terms like "wasteful," "ineffective," "inappropriate," "of unproven effectiveness," "unnecessary," and even "irrational" are used loosely and often interchangeably in the literature that is critical of current medical practice. Commentators have lamented the prevalence of unnecessary elective surgery, ${ }^{12}$ gratuitous "little ticket" diagnostic tests, ${ }^{13}$ and expensive treatments for AIDS patients. ${ }^{14}$ It is tempting to assume that these practices share some fundamental characteristic that places them within a unified category of wasteful medical treatments.

Although the temptation is evident, assimilating various "inappropriate" types of care within the rhetoric of waste cutting is at best confusing. Take the example of the rules that determine when physician office visits are "medically necessary." 15 As one physician explained it:

Medicare has set guidelines that for a given condition, you're only allowed to see patients so many times. That doesn't mean that you can't see them more often-you certainly can-but they won't pay for it. ...

It takes a great deal of time ... because I have to explain to them why Medicare may not pay for their visit to me. You're legally obliged to explain to the patient that this is considered medically unnecessary. Well, that choice of words implies to most patients that you're giving poor medical care. You're making them come back too often. And I think it's terrible.

12 See Robert H. Brook \& Kathleen N. Lohr, Will We Need To Ration Effective Health Care?, IssUES SCI. \& TECH., Fall 1986, at 68, 72.

${ }^{13}$ See Marcia Angell, Cost Containment and the Physician, 254 JAMA 1203, 1204 (1985).

14 See Todd Interview, supra note 7, at 23.

15 The rules to which we refer emanate from the Health Care Financing Administration. Although the precise content of these rules, as developed and enforced by HCFA's financial intermediaries, is confidential, a general description may be found in HEALTH CARE FIN. ADMIN., MEDICAL CARRIERS MANUAL $\$ 7500 \mathrm{ff}$. (HCFA Pub. 14) (1990). 
It wastes 20 minutes of my time explaining to them that no, its not really medically unnecessary, that that's just how Medicare has chosen to word the new form .... ${ }^{16}$

Making "expensive" synonymous with "medically unnecessary" seems a particularly troubling example of bureaucratically sanctioned linguistic drift. But it is not just linguistic territory that has been invaded by the waste cutters. Utilization review companies have moved beyond the realm of previewing surgical procedures and into the field of making allocational choices in the cases of very sick and dying patients. They employ "case managers" to direct the costly care of their sickest enrollees. This strategy can pay off handsomely. " $[\mathrm{M}]$ any cost-management companies are strengthening their 'case management' of patients who are seriously ill, with advanced cancer or AIDS, for example, or recovering from a stroke. 'The savings can average $\$ 10,000$ to $\$ 15,000$ per case and be as high as $\$ 400,000$.' 17 While some case managers may be truly wellintentioned, intervening to help patients and save them from painful overtreatment, they also represent economic interests that will inevitably conflict at times with the interests of the patient. In the future, we are likely to hear more from case managers about "inappropriate," "ineffective," and "medically unnecessary" care. When we do, it will be hard to know exactly what this means. Is the proposed treatment harmful or worthless? Is it futile or just too costly?

These ambiguities must be faced in formulating a sensible strategy for controlling the cost of medical care in America. It would be enormously agreeable if cost containment could be achieved by cutting out a homogeneous wedge of present practices (Figure 1). But our analysis suggests that waste is heterogeneous (Figure 2), a claim worth exploring at some length. We need to know more about the four different types of waste. How prevalent are they? How do we determine that particular treatments fall into one of the four categories? What political, social, and professional obstacles will arise when standards are introduced forbidding wasteful practices? Will waste-cutting erect barriers to beneficial care, or can waste-cutting bypass such choices in medical care

${ }^{16}$ Are Guidelines, Standards or Parameters Having an Impact on the Way You Practice Medicine, and How?, AM. MED. NEWS, Jan. 6, 1989, at 34, 34 (interviewing a private practitioner in St. Louis).

${ }^{17}$ Glenn Kramon, Taking a Scalpel to Health Costs, N.Y. TIMEs, Jan. 8, 1989, § 3, at 1,9 (quoting the vice-president of a cost management company). 
allocation? These four questions are at the core of the following section. Our main findings are summarized in Table I.

\section{A TAXONOMY OF "WASTE"}

\section{A. Ineffective (or Harmful) Treatment}

Some Americans, expert and lay, believe that much of medical care is ineffective or positively harmful. In part a generalized rebellion against authority of the $1960 \mathrm{~s}$, and nurtured by the consumer health movement of the $1970 \mathrm{~s}$, this view found a passionate voice in Ivan Illich's 1976 book, Medical Nemesis. ${ }^{18}$ His scathing critique of the medical profession's "poisons"19 and "black magic" ${ }^{20}$ never found widespread public acceptance. But the 1980s brought a wider condemnation of the medical profession. Today's conventional wisdom is that doctors have little idea of what they are doing.

Consider what doctors, to say nothing of patients, don't know about the value of just one procedure. Every year about $\mathbf{8 0 , 0 0 0}$ Americans get a carotid endarterectomy, a kind of Roto-Rooter job on clogged neck arteries. Typically costing $\$ 9,000$, counting the bill for a hospital stay, the operation is designed to prevent strokes. Another triumph of modern medicine? Or an overly risky, overdone alternative to cheaper drug therapy? Incredibly, no one knows for sure, and no one is tracking the patients on a systematic basis to find out.

The same holds true for scores of other medical ministrations. Food companies know the impact of a redesigned ketchup bottle on sales. But the virtuosos performing hysterectomies, installing pacemakers and bypassing diseased coronary arteries have only patchy information about the real payoffs. "Half of what the medical profession does is of unverified effectiveness," asserts Dr. Paul M. Ellwood, Jr. of Minneapolis, [one] in a phalanx of physicians who want to cut down on the guesswork. ${ }^{21}$

Academic medicine is trying to answer this criticism. Researchers in a relatively new branch of investigation, clinical epidemiology, are trying to sort out which medical maneuvers are effective.

18 IVAN ILIICH, MEdical Nemesis (1976).

${ }^{19} \mathrm{Id}$. at 44.

${ }^{20}$ Id. at 114 (emphasis omitted).

21 Edmund Faltermeyer, Medical Care's Next Revolution, FoRTUNE, Oct. 10, 1988, at $126,126$. 
Ideally, the research involves systematic and painstaking testing of therapies through randomized controlled clinical trials. But these experiments, the "gold standard" for determining clinical effectiveness, are events of epic proportion, lasting for years, costing millions of dollars, involving thousands of patients, facing monumental bureaucratic barriers, and raising serious ethical issues. ${ }^{22}$ Often, by the time clinical trials are completed, the technology they studied is outmoded. ${ }^{23}$ Although other methodologies have been developed and can yield useful information, ${ }^{24}$ physicians must regularly weigh the preponderance of imperfect evidence in order to estimate whether a particular patient might benefit from a particular intervention. ${ }^{25}$ It is often possible to entertain some reasonable doubt (or to hold out some reasonable hope) that a treatment will be effective. While there is currently a great deal of enthusiasm about improving the scientific basis of medicine, and while there is surely room for improvement, a vast project to make medicine scientific can never keep up with innovations in medical practice. Nor is it likely to provide firm ground for determining correct choices in most clinical situations. Medical decision-making is simply too complex. ${ }^{26}$

Given these limitations, how can ineffective treatments be identified? One approach is to augment imperfect information with the judgments of experts. Distinguished physicians, well-versed in the scientific literature, can use their clinical judgment-their beliefs about what works, based on their own past practices-to produce

22 See Arnold M. Epstein, The Outcomes Movement-Will It Get Us Where We Want to Go?, 323 NEw ENG. J. MED. 266, 268 (1990); David M. Eddy \& John Billings, The Quality of Medical Evidence: Implications for Quality of Care, HEALTH AFF., Spring 1988, at $19,28-29$.

${ }^{23}$ See Eddy \& Billings, supra note 22, at 28.

24 These other methodologies, often subsumed under the rubric of "observational epidemiology," are clearly elucidated in J. MARK ELLWOOD, CAUSAL RELATIONSHIPS IN MEDICINE: A PRACTICAL SYSTEM OF CRITICAL APPRAISAL (1988). For a nontechnical account of the pitfalls of such studies, see MAX MICHAEL ET AL., BIOMEDICAL BESTIARY: AN EPIDEMIOLOGIC GUIDE TO FLAWS AND FALLACIES IN THE MEDICAL LITERATURE (1984).

${ }^{25}$ See Epstein, supra note 22, at 268; Eddy \& Billings, supra note 22, at 20. We do not wish to create the impression that little of value is known about effectiveness in clinical medicine. As one of our readers, Dr. Colin Dayan, has pointed out, there are numerous cases in which researchers have conclusively demonstrated the effectiveness (or lack thereof) of particular interventions. These cases notwithstanding, no one doubts that much remains to be learned about the utility of present practices.

${ }^{26}$ See Robert W. Dubois \& Robert H. Brook, Assessing Clinical Decision Making: Is The Ideal System Feasible?, 25 INQUIRY 59, 63 (1988); Eddy \& Billings, supra note 22, at 24. 
estimates of effectiveness. And groups of physicians can combine their expert judgments to arrive at consensus. A group of researchers at the RAND Corporation has developed a method for generating this kind of professional consensus about what works (and what doesn't work) in medicine. ${ }^{27}$ Because their innovative method has been so widely acclaimed and so often held up as a model for cutting waste by making rules, it warrants a brief review.

The RAND group's goal was to develop practice parameters for several widely used operations. They assembled a panel of distinguished physicians for each of the operations, and each panel member reviewed the available scientific literature about the procedure. ${ }^{28}$ With a list of all of the possible clinical scenarios in which each procedure might be performed, each panelist made an assessment of the appropriateness of the intervention for each of the scenarios, based on the literature review and clinical judgment. After making independent assessments, the panel members met to discuss the cases and compare their ratings. They found there was substantial disagreement among them about the appropriateness of performing the operations in many clinical settings. ${ }^{29}$ And so, after reviewing the cases together, the individual physicians rated each scenario again, and the revised ratings were combined into a group consensus rating of the appropriateness of treatment in each situation. For each clinical scenario, the surgery was rated as "appropriate," "inappropriate," or "equivocal." "Inappropriate" care was treatment in which "the expected health benefit[s] (i.e., increased life expectancy, relief of pain, reduction in anxiety, [and] improved functional capacity) [were] exceeded [by] the expected negative consequences (i.e., mortality, morbidity, anxiety of anticipating the procedure, pain produced by the procedure, and time lost from work)." 30 Roughly speaking, then, "inappropriate" was defined to mean ineffective or harmful.

The ratings have been used successfully in pilot programs to identify "inappropriate" care. Two prominent RAND researchers recently left the Santa Monica think tank to found Value Health Sciences, Inc., bringing along the RAND methodology. They then

${ }^{27}$ For a discussion of the specific methods used to develop the appropriateness ratings, see Rolla E. Park et al., Physician Ratings of Appropriate Indications for Six Medical and Surgical Procedures, 76 AM. J. PUB. HEALTH 766 (1986).

${ }^{28}$ See id. at 767.

${ }^{29}$ See id. at 768-69.

${ }^{30}$ Id. at 767 . 
developed some innovative software that uses the expert consensus on appropriateness to deliver second opinions about physician's treatment choices. Value's clients employ utilization review nurses to quiz physicians about referrals for the selected procedures. Using Value's computer-driven questionnaire while talking over the telephone, the nurses gather information about prospective patients and then match each prospective patient to a previously rated clinical scenario. If the prior consensus suggested the operation was "appropriate" for that patient, the patient's insurance company pays for the hospital admission. If the rules identified the operation as "inappropriate," the procedure is not covered. The referring physician may then appeal the decision regarding coverage with a doctor representing the utilization review company. In a trial run by the Aetna insurance company, $15 \%$ of 1,000 referrals for procedures were judged "inappropropriate"; physician appeals brought the number of actual refusals down to $9 \% .{ }^{31}$

The successful implementation of the RAND/Value method is one of the first achievements of what has been called the "outcomes movement." 32 This informal coalition of academic researchers, government officials, physician professional organizations, and members of the health insurance industry has come together over the past three years in an effort to study what works in medicine, to define "appropriate" care, and to use that definition of appropriateness to eliminate allegedly wasteful care through the use of practice guidelines. While each participant has a slightly different sense of the movement's mission, ${ }^{33}$ most share Paul Ellwood's ambitious vision:

Outcomes management is a technology of patient experience designed to help patients, payers, and providers make rational medical care-related choices based on better insight into the effect of these choices on the patient's life. Outcomes management consists of a . . . language of health outcomes; a national data base

31 See Harris Meyer, Payers To Use Protocols To Assess Treatment Plans, AM. MED. NEws, Dec. 9, 1988, at 1,62-63. Actual refusal rates have increased, as early versions of the software have been replaced by more sophisticated programs. See telephone Interview with Dr. Robert DeBois, Senior Vice President of Value Health Sciences (Mar. 2, 1992); infra note 78 and accompanying text.

32 See Epstein, supra note 22, at 266.

${ }^{33}$ These differences in perception have taken several forms. Some participants have emphasized the movement's potential to cut costs, see Brook \& Lohr, supra note 12, at 68; Califano, supra note 6, at A25; Faltermeyer, supra note 21, at 126; others have highlighted its promise of harnessing scientific knowledge to enhance the quality 
containing information and analysis on clinical, financial and health outcomes that estimates as best we can the relation between medical interventions and health outcomes, as well as the relation between health outcomes and money; and an opportunity for each decision-maker to have access to the analyses that are relevant to the choices they must make. ${ }^{34}$

Federal officials have been enthusiastic supporters of what has been hailed-perhaps somewhat grandiosely-as "the third revolution in health care. ${ }^{\text {35 }}$ Former Health Care Financing Administration ("HCFA") director William L. Roper, under pressure to contain Medicare's explosive growth, announced a major initiative to "evaluate and improve medical practice" by using HCFA's mammoth databases to study the outcomes of care given under that program. ${ }^{36}$ In a related later development, the Department of Health and Human Services' National Center for Health Services Research

of medical care, see AGENCY For HEALTH CARE POLICY AND RESEARCH, U.S. DEP'T OF HEALTH AND HUMAN SERVS., RESEARCH ACTIVITIES 4 (1992) [hereinafter AHCPR, RESEARCH]; William L. Roper et al., Effectiveness in Health Care: An Initiative to Evaluate and Improve Medical Practice, 319 NEW ENG. J. MED. 1197, 1197 (1988). Some members have embraced the idea of using rules to audit physicians' practice choices, see supra notes 27-32 and accompanying text. Others, reluctant to promote "cookbook medicine," and believing that physicians will respond to education about "appropriate" practices, appear to prefer that adherence to guidelines be kept voluntary. See AHCPR, RESEARCH, supra, at 5. See also infra note 80. This preference may be optimistic in light of previous studies showing that physician practice choices are relatively resistant to the "practice suggestions" of experts. See, e.g., Jacqueline Kosecoff et al., Effects of the National Institutes of Health Consensus Development Program on Physician Practice, 258 JAMA 2708, 2712 (1987) (finding that consensus development conferences produced little change in patient care); Jonathan Lomas et al., Do Practice Guidelines Guide Practice? The Effect of Consensus Statements on the Practice of Physicians, 321 NEW ENG. J. MED. 1306, 1310 (1989) (concluding that while practice guidelines may affect "the perceptions of physicians," they alone are insufficient to alter physicians' behavior). Other incentives may be needed to modify practice patterns. The range of alternatives is canvassed in John M. Eisenberg, Physician Utilization: The State of Research About Physicians' Practice Patterns, 23 MED. CARE 461, 467-70 (1988).

Despite these differences in perception, it is undeniable that much of the enthusiasm (and funding) behind the outcomes movement has been driven by the perception that it will slow the rising cost of medical care expenditures, and it is clear that many of the key participants view the development of a link between "appropriate" practices and reimbursement as a foregone conclusion. See infra notes $40-42$ and accompanying text. In this essay, we explore the implications of implementing such a policy.

${ }^{34}$ Paul M. Ellwood, Shattuck Lecture-Outcomes Management: A Technology of Patient Experience, 318 NEW ENG. J. MED. 1549, 1551 (1988).

${ }^{35}$ Arnold S. Relman, Assessment and Accountability: The Third Revolution in Health Care, 319 NEW ENG. J. MED. 1220, 1220 (1988).

${ }^{36}$ See Roper et al., supra note 33, at 1197. 
("NCHSR") was renamed the Agency for Health Care Policy and Research ("AHCPR") and charged with "promoting the quality, appropriateness, and effectiveness of health care" and directing studies that would lead to the development of clinical guidelines for "treatments or conditions that account for a significant portion of Medicare expenditures. ${ }^{n 7}$ With the new name came an increase in federal funding. In 1991, the agency received over sixty million dollars to investigate the outcomes of medical care and develop parameters to guide clinical practice. ${ }^{38}$ Three years earlier, as the NCHSR, the agency had been given less than two million dollars to support such efforts. ${ }^{39}$ Many leaders of private industry and health insurance firms are enthusiastic about these developments, and foresee using the results to cut costs. ${ }^{40}$

The American Medical Association ("AMA") is perhaps the least likely of the coalition's members. Historically a staunch advocate of physician autonomy, the AMA has teamed up with the RAND Corporation and the Academic Medical Center Consortium, a group of major teaching hospitals, ${ }^{41}$ to develop practice guidelines for

${ }^{37}$ AHCPR, PROGRAM NOTE, supra note 8, at 6 (quoting the Legislative Summary to the Omnibus Budget and Reconciliation Act of 1989). Although the AHCPR has been the beneficiary of congressional enthusiasm for medical care cost savings, the Agency's leaders have recently become eager to avoid disappointment, disclaiming a connection between guideline development and cost containment. As the Agency released the first of its guidelines this spring, its director, Dr. J. Jarrett Clinton, remarked that,

"[t]here are those in Congress who hoped, and still hope, that this effort would be a cost-savings device, but it has limited use for this purpose. . . . This is not about cost-cutting, but about getting the best value per dollar spent in the long run. In some cases, for instance, the guidelines may result in spending more money on some things.

Warren E. Leary, More Advice for Doctors: U.S. Guides on Treatments, N.Y. TIMES, Apr. 15, 1992, at C14. Despite its position in the forefront of the outcomes movement, then, the Agency's perception of the movement's direction may be at odds with that of some of the movement's members and supporters, including some members of Congress, the insurance industry, the business community, and some academic researchers.

${ }^{38}$ See House Subcommittee Votes Level Funding for AHCPR and HCFA: Senate Likely to Increase Support for AHCPR, HSR REPORTS (Association for Health Services Research, Washington, D.C.), June 1991, at 1, 5.

${ }^{39}$ See Epstein, supra note 22, at 266.

${ }^{40}$ For example, Blue Cross and Blue Shield executive Bernard T. Tresnowski, when asked about the practice parameters approach, responded: "Right On!" See Faltermeyer, supra note 21, at 132. "With better data," it is believed, "business could effectively challenge proposed treatments." Id. at 126.

41 See Report of the Board of Trustees of the American Medical Association, Practice Parameters 4 (1990) [hereinafter AMA Trustees' Report] (unpublished 
use by "payers and utilization and medical reviewers to define a range of practice options physicians could use without incurring financial or other sanctions ...."42 The AMA's embrace of the parameters initiative is somewhat puzzling-few physicians wish to do their patients harm, but none seem to want to be told what to do-organized medicine's position probably reflects the recognition that "if you can't beat 'em, join 'em." As AMA Executive Vice President James Todd explained, physicians must lead the effort to develop practice standards because they "can't afford to abdicate this responsibility to [the] bureaucratic computer screens of HCFA or commercial insurance companies." ${ }^{\text {43 }}$ Although support for the initiative must be viewed primarily as a kind of preemptive strike, practice parameters do offer some attractive features from the physicians' perspective. ${ }^{44}$ First, they have a substantial educational potential. In a bewilderingly complex and rapidly changing technical environment, parameters can provide physicians with simple, easily accessible reference guide. Second, in a hostile legal environment, adherence to "appropriate" practices may protect practitioners from malpractice liability. ${ }^{45}$

In summary, parameters do hold some promise in curbing ineffective or harmful care, and there is clearly energetic activity in support of their development. But the amount of time and money required to develop and implement the RAND/Value approach on a large scale, though unknown, is surely substantial. According to AHCPR officials, it has taken three years to move from the process of identifying conditions for guideline development to early pilot testing of those guidelines; the agency released two guidelines in March 1992, intending to make several more available this summer. ${ }^{46}$ If such guidelines were to be widely used to audit physi-

report, on file with authors).

${ }^{42}$ Sharon McIlrath, AMA, Rand Corp. Plan Joint Development of Practice Guidelines, AM. MED. NEws, Oct. 28, 1988, at 2, 2.

${ }^{43}$ Todd Interview, supra note 7 , at 25.

${ }^{44}$ For an analysis by a physician and leading researcher in the outcomes movement stressing the advantages of practice parameters, see Robert H. Brook, Practice Guidelines and Practicing Medicine: Are They Compatible?, 262 JAMA 3027, 3030 (1989).

${ }^{45}$ The relationship between practice guidelines and malpractice liability remains a point of considerable controversy among commentators. See infra notes 67-70 and accompanying text.

${ }^{46}$ See telephone Interview with Robert Isquith, Chief of Public Affairs, AHCPR (Mar. 3, 1992); telephone Interview with Stephen H. King, M.D., Chief Medical Officer, AHCPR (July 15, 1991). 
cian choices, the degree of bureaucratization in medical care would increase substantially. The requirement that physicians "clear" a large proportion of their decisions could impose significant additional costs in a system where, experts estimate, as much as $20 \%$ of expenditures already go to administrative matters, ${ }^{47}$ and where provider frustration with the micromanagement of care is already intense. ${ }^{48}$ Still, the movement has generated tremendous enthusiasm and significant funding. It is worth exploring the probable consequences of extending its approach to other types of "wasteful" care.

\section{B. Treatment of Uncertain Effectiveness}

Dr. Ellwood's estimate that "half of what the medical profession does is of unverified effectiveness ${ }^{\$ 49}$ is undeniably provocative. If that were the case, policymakers might well be advised to discontinue such practices pending scientific demonstration of their worth. Although this could mean waiting decades for research results, the successful implementation of this policy might cut medical costs dramatically. ${ }^{50}$

There is ample room for doubt about the effectiveness of many medical treatments. For some treatments, there is very little data on effectiveness. For most treatments, there is disagreement as to how to interpret the available data. In the face of this uncertainty, how

${ }^{47}$ See Steffie Woolhandler and David U. Himmelstein, The Deteriorating Administrative Efficiency of the U.S. Health Care System, 324 NEw ENG. J. MED. 1253, 1254-55 (1991).

${ }^{48}$ See Gerald W. Grumet, Health Care Rationing Through Inconvenience: The Third Party's Secret Weapon, 321 NEW ENG. J. MED. 607, 608 (1988).

${ }^{49}$ Faltermeyer, supra note 21 (quoting Dr. Paul M. Ellwood).

${ }^{50}$ This option is discussed in detail in Brook, supra note 44 , at 3029 . The idea behind "of uncertain effectiveness" would seem to correspond with the RAND categorization "equivocal." See Park et al., supra note 27, at 767. Much of the popular commentary following the release of the RAND results, see supra text accompanying notes $\mathbf{3 1 - 3 4}$, conveyed the impression that half of all coronary bypass surgery had been discovered to be medically unnecessary. See supra note 6 . Yet the RAND group's findings categorized 14\% of such surgeries as "inappropriate," while $30 \%$ were classed as "equivocal"; it would thus appear that procedures falling under both of these headings were lumped together in arriving at the "one-half" estimate. See Constance M. Winslow et al., The Appropriateness of Performing Coronary Artery Bypass Surgery, 260 JAMA 505, 509 (1988). We contend that, from the perspective of health care policymaking, "inappropriate" and "equivocal" procedures are quite different, and that programs aimed at cutting these two distinct types of "waste" would for that reason meet quite different fates. 
feasible is it to talk about cutting waste with rules prohibiting payment for treatments of undetermined effectiveness?

Most physicians would almost certainly oppose this approach. Because of the lack of scientific knowledge about disease, the practice of medicine is not a "cookbook" endeavor. Clinicians extrapolate beyond scientific data in "the large portion of cases . . . [that] are clinically gray and require clinical judgment. ${ }^{51}$ Judging how to proceed in questionable cases is part of what constitutes the art of medicine. Physician Donald Berwick of the Harvard Community Health Plan has rightly warned that in choosing to cut waste by overriding clinical judgment, "we [may] gain control of care patterns only to find that care is being given by doctors who have lost pride and heart. ${ }^{52}$ And while the specter of disheartened physicians might not forestall officials intent upon cutting costs, public opinion would likely inhibit this approach to "cutting waste." Some patients would surely be outraged at being denied treatment simply because scientific data is lacking. The relatively minor turbulence that has attended the denial of "questionable" drugs to AIDS patients, along with the success that AIDS advocates have had in modifying and bypassing bureaucratic obstacles, foreshadows the uproar that would attend widespread denial of "questionable" care. For example, the constituency of patients with heart disease is unquestionably broader and more powerful than those with AIDS; many of the wellestablished technologies in this area are of uncertain benefit for many types of patients. It is implausible to expect that heart-disease victims would quietly forego potentially lifesaving treatment in the name of scientific purity. In short, if "wasteful" means "of uncertain effectiveness," cutting waste by making rules faces substantial popular and professional opposition.

\section{Treatment That Is Ethically Troubling}

The explosive growth of the bioethics field, an area that was virtually nonexistent a generation ago, testifies to the proliferation of ethically troubling medical treatment. ${ }^{53}$ The use of aggressive medical therapies in treating the very old, the very young, and the very sick has engendered some of the most vehement charges of

51 Meyer, supra note 31, at 63.

52 McIlrath, supra note 42 , at 41 .

${ }^{53}$ A fascinating analysis of these developments can be found in DAviD J. ROTHMAN, STRANGERS AT THE BEDSIDE: A HISTORY OF HOW LAW AND BIOETHICS TRANSFORMED MEDICAL DECISION MAKING (1991). 
"waste," "inappropriateness," and "irrationality" in American medicine.

Rulemaking in this area requires an ethical consensus concerning an appropriate level of care. For people who are intimately acquainted with instances of gross overtreatment, this often seems a trivial problem. Waste is apparent and outrageous. Something like Justice Stewart's standard for obscenity- "I know it when I see it"-seems to hold. But experience shows that even the seemingly clearest cases can evoke controversy (if not litigation), bringing into conflict those most intimately familiar with the patient's situation. These controversies often reflect fundamental disagreements about the goals and obligations of providers, payers, and patients, or even disputes about the significance of human life, including a "right to life." We will not recapitulate the bioethical debates surrounding these issues. ${ }^{54}$ It is enough to note that the term "wasteful" is used here in an entirely different sense than in the previous two sections. No literature search or scientific experiment satisfactorily speaks to this issue of "waste." No consensus panel can settle the ethical question of what is futile, desirable, or even cruel.

What then are the possibilities for policy in this area? What kinds of rules can be made to cut waste in ethically problematic cases? Significant progress has been made in defining when it is permissible to terminate care. Guidelines developed in the bioethics community have informed court decisions and state statutes. ${ }^{55}$ Such policies undoubtedly can help in guiding individual decisions, but their impact on the overall allocation of medical resources is unknown. Such guidelines, however, are not analogous to the RAND/Value procedures to "cut waste." Little progress has been

54 See generally DaNIEL GaLlaHAN, SETTING LIMTTS: MEDICAL GOALS IN AN AGING SOCIETY (1987) (contending that medical care should be rationed based on age); NORMAN DANIELS, AM I MY PARENTS KEEPER? AN ESSAY ON JUSTICE BETWEEN THE YOUNG AND THE OLD (1988) (examining the competing claims of the young and the elderly to medical resources); NORMAN DANIELS, JUST HEALTH CARE (1985) (arguing that a principle of equality of opportunity should guide distribution of health care services); A.A. Scitovsky and A.M. Capron, Medical Care at the End of Life: The Interaction of Economics and Ethics, 7 ANN. REV. PUB. HEALTH 59 (1986) (analyzing the ethical implications of devoting a disproportionate amount of medical resources to the aged); Anne A. Scitovsky, "The High Cost of Dying": What Do the Data Show?, 62 MILBANK MEMORIAL FUND Q. 591 (1984) (same).

${ }^{55}$ See, e.g., In re Conroy, 486 A.2d 1209, 1220 (N.J. 1985) (citing President's Commission for the Study of Ethical Problems, in MEDICINE AND BIOMEDICAL AND BEHAVIORAL RESEARCH, DECIDING TO FOREgo LIFE-SUSTAINING TREATMENT 23 (1983) in an analysis of the question of when life-sustaining treatment may be withdrawn from legally incompetent patients). 
made in developing analogous rules in this area, rules that would say when wastefulness makes it obligatory to deny or terminate care. (It should be emphasized, moreover, that no one connected with the landmark RAND studies has proposed that any such rules be made.)

Their very suggestion is enormously controversial, as illustrated by the reception that greeted Daniel Callahan's proposal that age be a criterion in the allocation of public funds for medical care. ${ }^{56}$ Highlighted on the op-ed pages of the New York Times, ${ }^{57}$ the proposal drew vociferous attacks from gerontologists, senior-citizen advocates, and the elderly themselves. Social critic Nat Hentoff branded the scheme "morally depraved," a comment that was duly noted in the American Association of Retired People's News Bulletin. ${ }^{58}$ Further discussion was effectively ended. If "wasteful" means "ethically troubling," cutting wasteful care means facing hard and bitter choices. In matters of life and death, when values clash, proposing allocational rules can place those rules beyond reasonable public discussion. It is difficult to imagine how such a process could lead to public consensus.

\section{Treatment That Is Not Allocationally Efficient}

Notwithstanding the above difficulties, bread-and-butter medicine is not about complex ethical issues. Rather, increasingly it is about expensive medical care options. Today's physicians must choose daily from among various costly treatments and tests, many of which are unquestionably beneficial. Consider these lifesaving treatments:

(1) Early Cancer Detection (e.g., annual mammography for women aged 40-50). Since women in this age group have a low incidence of breast cancer, annual mammography offers a modest improvement in life expectancy at a significant financial and social cost. Screening $25 \%$ of all American women in this age group on an annual basis would save 373 lives each year. Costs (in 1984 dollars) would be $\$ 408$ million for mammography, surgical workups, and continuing care. Savings from early detection of cancer would be

56 See CallaHaN, supra note 54.

${ }^{57}$ See Daniel Callahan, Rethinking Health Care for the Aged, N.Y. TIMES, Sept. 25, 1987, at A39.

58 See Health Debate Rages Over Rationing By Age, AARP News BULL., June 1988, at 1 (quoting comments made by Nat Hentoff at a debate sponsored by the National Council on the Aging). 
$\$ 6$ million annually, resulting in a net annual cost of $\$ 402$ million dollars to save 373 lives. ${ }^{59}$

(2) Safer Diagnostic Tests (e.g., nonionic contrast medium). Contrast medium is a liquid which, when injected into the bloodstream, circulates throughout the body making blood vessels and certain organs more visible on $\mathrm{x}$-ray. Injection with the dye carries a certain risk of a fatal allergic reaction. Recently, a nonionic contrast dye was introduced that is safer for patients. The risk of death from injection with the new dye is 1 in 250,000 (an improvement over the risk of 1 in 30,000 with the older dye). The newer dye costs 10 times as much as the older one, and widespread adoption could cost as much as one billion dollars annually nationwide. ${ }^{60}$

(3) Organ Transplantation (e.g., heart transplantation). Heart replacement is surprisingly effective in the treatment of end-stage heart disease. Recipients enjoy a 75-80\% one-year survival rate. Although only 346 cardiac transplants were performed in 1984, an estimated 50,000 people could benefit from the procedure each year. Heart transplantation costs between $\$ 70,000$ and $\$ 200,000$ per patient. $^{61}$

When do expensive maneuvers become "wasteful?" Traditionally, policymakers have approached this problem from the framework of cost-benefit analysis. ${ }^{62}$ Given a rank ordering of medical programs and procedures, beginning with the one with the best cost-to-benefit profile and ending with the one with the least

${ }^{59}$ See David M. Eddy et al., The Value of Mammography Screening in Women Under Age 50 Years, 259 JAMA 1512, 1512-19 (1988). For completeness we should note that the case is more complicated than suggested above. Though the point remains that mammography is of relatively low benefit to young women, some significant health costs, such as the risk of a false positive test, are not mentioned. For example, out of one hundred women undergoing mammography, one will be referred for a breast biopsy to investigate a radiologic abnormality that turns out not to be cancer. This raises the question of whether the health and social cost of tens of thousands of unnecessary surgeries each year outweighs the benefit of a few hundred lives saved. For an analysis that emphasizes these costs, see John C. Bailar, Mammography Before Age 50 Years?, 259 JAMA 1548-49 (1988). at 47 .

${ }^{60}$ See Annetta Miller et al., Can You Afford To Get Sick?, NewswEEk, Jan. 30, 1989,

61 See Robert H. Blank, Rationing Medicine 41 (1988).

62 Cost-benefit analysis is but one form of utilitarian program analysis. Other methods include cost-utility analysis and cost-effectiveness analysis. The application of these techniques to medical care is thoroughly discussed in MICHAEL F. DRUMMOND ET AL., METHODS FOR THE ECONOMIC EVALUATION OF HEALTH CARE PROGRAMMES 74167 (1987). In this section, we refer to cost-benefit analysis, but many of our comments apply as well to the other related forms of analysis. 
attractive profile, one might simply allocate money from the top down. Above some cutoff point, the listed interventions could be considered "worthwhile"; below that point, "wasteful." There are, however, three significant obstacles to implementing such a plan in American medicine.

The first is the unavailability of a defensible rank ordering. We have scant information about the effectiveness and costs of most clinical interventions. Moreover, we lack a firm conceptual and empirical basis for equating different kinds of medical, social, and financial benefits. In the absence of these two sorts of information, it is difficult to assign meaningful cost-benefit estimates to medical procedures. ${ }^{63}$ The second difficulty is that the American medical care system does not operate within a fixed budget (nor do most American physicians). Without a budgetary limit, the borderline between "worthwhile" and "wasteful" simply cannot be defined. It is impossible to say which interventions would fall below a purely hypothetical cut-off. A final obstacle arises from our decentralized system of financing. We have no guarantee that cuts in "wasteful" expenditures will be compensated with shifts toward "worthwhile" expenditures. We may agree that annual mammographic screening for young women is comparatively wasteful, but we have no reason to believe that money saved by abstaining from mammography will be spent on a more worthwhile endeavor, such as universal access to prenatal care.

While rigorous cost-benefit analysis is unlikely to govern the allocation of medical services in the foreseeable future, concerns about costs and benefits will continue to have an important place in discussions of "wasteful" care. This is surely appropriate, since no medical care system can provide all possible services. But when "not cost effective" is taken to be synonymous with "wasteful," some misleading inferences can follow. One of these is the suggestion that treatments that fall below the cost-benefit cutoff point are "wasteful," and therefore do no one much good. This is certainly not true. There are many potentially lifesaving treatments that are

63 The theoretical difficulties involved are discussed in some detail in BLANK, supra note 61, at 115-16. An actual illustration arose in Oregon, where the rigorous application of cost-benefit techniques led to a rank ordering of therapies in which the treatment of crooked teeth was placed above therapy for early Hodgkin's disease, and treatment for thumb-sucking was put above hospitalization of a starving child. See Fox \& Leichter, supra note 4, at 22. Although this original list was subsequently reordered, the initial result exposes the conceptual and empirical weakness of utilitarian program analysis, as it applies to medical care. 
very costly, but effective (breast-cancer screening in young women, safer diagnostic tests, and organ transplantation all fall into this category). When cutting waste on economic grounds, we inevitably eliminate some services that do some good. We should therefore not be surprised to find people fighting for access to treatments that are "not cost-effective," as did the members of the Komen Foundation for Breast Cancer in Dallas, a group of wealthy and socially prominent Republican women who successfully lobbied the Texas legislature in 1989 to require that insurance companies cover the cost of screening mammography to all women ages 35 and over. ${ }^{64}$

Such episodes lay bare the link between "waste cutting" and "rationing." If "waste cutting" means "trimming the fat," and "rationing" means "making rules to limit the use of beneficial services," it will necessarily be the case that in trimming fat we deny some people some beneficial services. What is particularly striking is that the perception of benefit determines the political cost of waste cutting. While the medical costs of denying young women access to screening mammography are quite small (as the analysis cited above demonstrates), the political price may be prohibitive (as the Texas legislators found out). Similarly, in the recent Oregon "rationing" movement, procedures were initially ranked according to their alleged cost-to-benefit profiles. Organ transplants were near the bottom in this initial list of services, but the political costs of cutting this form of "waste" were seen as too great, and organ transplants were moved upward on the list so that they would qualify for Medicaid reimbursement. ${ }^{65}$ Cutting waste, when waste is either of great benefit or is perceived to be so, can be prohibitively expensive politically.

More generally, economically driven rulemaking runs counter to those American values and institutions favoring aggressive, hightechnology, "do something" medicine. Opinion polls show that Americans believe, nearly unanimously, that financial considerations should not enter into life-and-death medical decisions. ${ }^{66}$ In the legal arena, technological imperatives dovetail with our shared notions of individual rights and professional responsibilities,

${ }^{64}$ See Jane Gross, Turning Disease Into Political Cause: First AIDS, and Now Breast Cancer, N.Y. TIMEs, Jan. 7, 1991, at A12.

65 See Fox \& Leichter, supra note 4, at 23.

${ }^{66}$ See Robert J. Blendon, The Public's View of the Future of Health Care, 259 JAMA 3587,3590 (1987). 
meaning that rulemaking could exacerbate an increasingly unacceptable malpractice environment. As people who are injured by denial of care seek restitution, several issues will be at stake: Can care be denied because it is too expensive? When harm results from denial of treatment, who is responsible? What are the responsibilities of payers and providers? Already, some interesting cases have been heard. A Washington state court recently held that a third-party payer had a duty to pay for a man's liver transplant because his life depended on it. ${ }^{67}$ A Michigan woman with colon cancer has sued her HMO, maintaining that their cost-containment rules led to a delay in the detection of her malignancy. ${ }^{68}$

While commentators agree that the relationship between the malpractice standard and care cost containment is one of the most important issues confronting medical tort law in the 1990s, they are divided on how the legal system will accommodate rulemaking. Some argue that physicians who prudently adopt recommended sparer practice styles will find protection in the event of adverse outcomes. ${ }^{69}$ Others are doubtful that the accommodation can be made so smoothly, and fear that economically based rulemaking will "create enormous confusion and, quite likely, place physicians under inappropriate and unfair economic and legal pressures $\$ 70$ as they are forced to make choices between their own professional standards and payers' rules.

Whatever the political and legal outcomes, it is clear that economically driven rulemaking could force physicians to redefine their professional roles. Many physicians find such rulemaking unacceptable, ${ }^{71}$ and many believe that cost containment measures seriously compromise the quality of medical care. ${ }^{72}$ Some hold

67 See BLANK, supra note 61, at 137.

${ }^{68}$ See Harris Meyer, Managed Care: HMOs Tighten Their Belts, Look to Hybrid Plans and Brighter Future, AM. MED. NEwS, Jan. 6, 1989, at 12, 12.

${ }^{69}$ See Troyen A. Brennan, Practice Guidelines and Malpractice Litigation: Collision or Cohesion?, $16 \mathrm{~J}$. HEALTH POL. POL'y \& L. 67, 68; see also Mark A. Hall, The Malpractice Standard Under Health Care Cost Containment, 17 L. MED. \& HEALTH GARE 347,353 (1984) (arguing that the "law is fully capable ... of recognizing the ... emergence of cost incentives").

${ }^{70}$ E. Haavi Morreim, Stratified Scarcity: Redefining the Standard of Care, 17 L. MED. \& HeAlTH CARE 356, 356 (1989).

${ }^{71}$ See Leighton Ku and Dena Fisher, The Attitudes of Physicians Toward Health Care Cost-Containment Policies, 25 HEALTH SERVICES RES. 25, 25 (1990).

72 See. e.g., Martin I. Broder, The Impact of Cost Containment on Clinical Care (Mar. 16-17, 1987), in THE HeALTH CARE CosT CoNTAINMENT MOVEMENT: A RECONSIDERATION 9 (Report of a conference sponsored by Medicine in the Public Interest, 1988) (arguing that cost-containment programs have had a "disturbing" impact on patient 
that consideration of costs simply has no place in the practice of medicine. One frequently quoted passage draws a parallel between the obligations of physicians to their patients and the responsibilities of attorneys to their clients:

[P]hysicians are required to do everything that they believe may benefit each patient without regard to costs or other societal considerations. In caring for an individual patient, the doctor must act solely as that patient's advocate, against the apparent interests of society as a whole, if necessary. An analogy can be drawn with the role of a lawyer defending a client against a criminal charge. The attorney is obligated to use all ethical means to defend the client, regardless of the cost of prolonged legal proceedings or even of the possibility that a guilty person may be acquitted through skillful advocacy. Similarly, in the practice of medicine, physicians are obligated to do all that they can for their patients without regard to any costs to society. ${ }^{73}$

This attitude, which one might call the "professional imperative," dominates American medical practice, and it will not disappear overnight.

\section{REALISTIC Prospects For RULEMAKING}

This brief survey of the policy to cut waste by rulemaking has revealed that it is really many policies-at least as many policies as there are kinds of waste. Three summary points should be emphasized. First, there are different senses in which treatments are "wasteful." We know that some treatments are wasteful by looking at their results; in other cases we need to examine their price tag; in still others we must make a moral judgement. While this is not a profound point, it is one that is frequently obscured in the rhetoric of waste-cutting. Medicare's rules about medical necessity (and a myriad of similarly disingenuous policies) create confusion, breed cynicism, and offer little promise as long-term strategies to guide the allocation of medical services. ${ }^{74}$

care).

${ }^{73}$ Norman G. Levinsky, The Doctor's Master, 311 NEw ENG. J. MED. 1573, 1573 (1984).

74 The extent to which such rules can lead to bitterness, cynicism, and professional disengagement is well illustrated in a physician's report of his final 18 hospital visits to an 84-year-old woman dying of lung cancer, visits deemed to be "medically unnecessary." See Kenneth M. Prager, Medicare Meddling, N.Y. TimEs, Sept. 12, 1988, at A21. 
Second, since "waste" is diverse, policies to "cut waste" face different prospects for success. Although some forms of care can probably be prohibited with little resistance, this is not likely to be the case generally. There will be substantial professional, political, ethical, and legal obstacles to cutting waste in many cases. Although identification of wasteful practices may be conceptually straightforward, the costs of rulemaking may be high. Rules can work, but these obstacles must be faced squarely in attempts to develop coherent and realistic health policy.

Third, because the spectrum of "wasteful" care includes care that is effective, cutting waste by making rules will not always circumvent hard choices. Sometimes it may mean eliminating care that is both needed and beneficial. In other cases, it may mean cutting services that are perceived to be beneficial but are of uncertain effectiveness. In either case, we must watch out for immoderate promises about painless "waste cutting."

While doubts about rulemaking are warranted, nihilism is not. We all stand to gain from the knowledge that will flow from the outcomes movement, and rulemaking may work in some situations. As we have shown, rulemaking is likely to be particularly successful when the treatment in question is clearly ineffective or harmful. It is, however, far from obvious that such instances are sufficiently prevalent to justify the extravagant optimism surrounding the movement's likely impact. While the oft-cited RAND study of three commonly performed procedures showed that they were performed "inappropriately" in one-third to one-sixth of the cases, ${ }^{75}$ this figure in all likelihood overstates the prevalence of ineffective or harmful care for three reasons. First, the three procedures were apparently chosen precisely because the indications for their use are unclear. Given this uncertainty, it is not surprising that they were often used "inappropriately." Second, the RAND ratings were based on a retrospective review of medical records. It is likely that incomplete documentation produced a number of cases incorrectly rated as "inappropriate." This interpretation is supported by data from two published cases in which the appropriateness criteria were used prospectively. In both cases, inappropriateness rates were simply not as impressive as might have been hoped. In the early Aetna/

75 See Mark R. Chassin et al., Does Inappropriate Use Explain Geographic Variations in the Use of Health Care Services? A Study of Three Procedures, 258 JAMA 2533, 2535 (1987).

${ }^{76}$ See Epstein, supra note 22, at 268. 
Value trial, only $9 \%$ of the proposed services were ultimately deemed not appropriate for reimbursement. ${ }^{77}$ In a more recent trial of the Value software at five Blue Cross and Blue Shield plans, preauthorization review yielded a judgment of inappropriateness for $11 \%$ of the cases overall. ${ }^{78}$

Let us assume that $11 \%$ of all present medical practices are demonstrably ineffective or harmful. Eliminating those wasteful practices would result in substantial savings, given our present level of expenditure-an attractive prospect indeed. But are savings of that magnitude likely to be realized in the near future? It seems likely that implementation would take place over a period of years, given the AHCPR's past (and admirable) record of crafting guidelines carefully. ${ }^{79}$ After developing guidelines, a strategy will have to be developed to change physician behavior. Whether that strategy relies on "education"-as the AHCPR would apparently prefer $^{80}$-or on a RAND/Value-like direct linkage to reimbursement, ${ }^{81}$ it is clear that it would begin to have its intended effect only after a period of years.

If this is the case, how can rulemaking affect our level of medical care spending over the next decade? Providing a precise answer to this question would require us to address issues of health

${ }_{77}$ See Meyer, supra note 31, at 63.

${ }^{78}$ See Blue Cross and Blue Shield Association, Preauthorization Review System Finds More than 10 Percent of Medical Procedures Inappropriate, 8 MED. BENEFITS 3, 3 (1991). In this case, inappropriate rates varied substantially by procedure, with $27 \%$ of the proposed tonsillectomies judged to be inappropriate, but none of the proposed heart bypass surgeries or carotid endarterectomies so rated. See $i d$. The finding of no inappropriate operations out of the 181 bypass procedures is particularly striking in view of the voluminous commentary about the magnitude of "waste" in this category.

${ }^{79}$ Other organizations are actively engaged in developing guidelines. For example, many of the medical specialty societies have begun working on parameter development, and by October 1990 had reportedly constructed some 1,000 different guidelines. See AMA Trustees' Report, supra note 41, at 2. While this work signals enthusiasm for the parameters approach, it also raises the question of how to coordinate the efforts of those involved in the movement to enhance appropriateness and cut waste.

${ }^{80}$ See AGENCY FOR HEALTH CARE POLICY AND RESEARCH, U.S. DEP'T OF HEALTH AND HUMAN SERVICES, AHCPR PUB. NO. 91-0004, REPORT TO CONGRESS: ProgresS OF RESEARCH ON OUTCOMES OF HEALTH CARE SERVICES AND PROCEDURES 13-14 (1991) (discussing the dissemination of information about new technologies and ineffective practices). Policymakers at the agency are working to develop methods to effect change via parameter dissemination, see id., since they are aware of prior studies showing that the practices of physicians are relatively resistant to the "suggestions" of experts, see supra note 33 .

81 If rulemaking is linked to reimbursement, rules will have to be adopted by many or all payors to achieve widespread savings. 
economics that are beyond the scope of the present paper. But one can see that the possible $11 \%$ savings-particularly a savings achieved gradually-would inevitably be dwarfed by the losses exacted by the present rate of medical care inflation, which one expert has estimated to occur at a real rate of $7 \%$ per annum. ${ }^{82}$ Unfortunately, the plan to cut waste by making rules simply does not address this cost, one of the central problems of health services allocation. Eliminating today's waste cannot help us constrain the escalation of costs attributable to the more effective and more expensive services to be developed tomorrow. Viewed from this perspective, cutting waste by making rules is, at best, an incremental reform that might produce modest gains over the medium term. Despite the claims of its more ardent supporters, it shows little promise as a solution to the so-called "health care cost crisis."

In the end, the parameters movement may founder-not because of a lack of "wasteful" medical care, but because government and business leaders want a quicker fix to the problem of rising medical care costs. With wasteful care on the public's mind, a coalition of resourceful researchers, government officials, politicians, business leaders, and professional organizations have developed a vision of a world in which scientific know-how aided by computerized wizardry will produce rules for allocating the "right" amount of medical care. But the public's "issue attention cycle" waxes and wanes quickly. ${ }^{83}$ As it becomes clear that it would be years before hoped-for economic gains could be realized, and that cuts in "waste" entail significant social costs, the movement could lose some of its momentum and funding. As the AHCPR's director recently remarked to an audience of health-services researchers:

We have a wonderful opportunity to make outcomes and effectiveness research a very important incremental chapter in the pursuit

82 See Schwartz, supra note 4, at 220 . It is worth stopping to consider the magnitude of potential economic gains even under the most generous assumptions. If we assume that rulemaking and waste-cutting could be implemented for all medical practices over a one-year period (i.e., with $11 \%$ of present costs instantaneously eliminated), at the end of a decade our health expenditures would total over $175 \%$ of real current expenditures, assuming that the $7 \%$ real inflation rate prevails. If we did not adopt the plan to cut waste, our medical costs at the end of a decade would be nearly $200 \%$ of their real present level, again assuming that inflation continues unabated. If the program to cut waste were adopted more gradually, the difference between the economic outcomes under the two scenarios would narrow accordingly.

${ }^{83}$ See generally Anthony Downs, Up and Down with Ecology-the "Issue Attention Cycle, " 28 PUB. INTEREST 39, 39 (1972) (noting that "American public attention rarely remains sharply focused upon any one domestic issue for very long"). 
of quality and value for the health care dollar. I believe that window is only going to be open so long. The Congress indeed expects things tomorrow, and I believe that with reasonable progress reports from you, I can be a part of telling them that good work takes time. At the same time, if we say that it takes five to six years and please hold your breath, then I think we'll lose. So as I said to the [outcomes research] teams that were assembled here a few days ago, we're delighted at the progress you're making, but hurry up. ${ }^{84}$

\section{Is TḦere AN Alternative to RulEMAKING?}

Nothing above is intended to imply that there is a simple solution to the problem of rising medical expenditures. The "professional imperative" that drives physicians to provide more, better, and safer services (and the desire for better health that drives patients to seek the same) will continue. If we are to curb rising costs, powerful countervailing forces must be brought to bear. Rules can certainly help in applying such forces, and the parameters movement is well underway. But is rulemaking the most promising course of action? Any answer must take into account two decades of frustrating failure to contain health expenditures in America. During that time, there were numerous attempts to change the way in which America delivers, pays for, and regulates medical care. None has been demonstrably successful in curbing medical care inflation or in constraining the growth in the intensity of services provided. Neither competition, managed care, prospective payment, nor numerous other purported panaceas has fulfilled its promise. Each in its day was touted as the answer to the problem of rising costs, leading to cycles of delight and disappointment ${ }^{85}$ as expenditures resumed their seemingly inexorable rise, or costs were shifted onto other sectors of the medical care economy. To expect more of the outcomes movement would be to ignore the lessons of experience. It is worth sketching what these lessons might be.

During the same twenty year period that costs rose in this country, other nations had substantially greater success in control-

${ }^{84} \mathrm{~J}$. Jarrett Clinton, Address to the Tenth Anniversary Meeting of the Association for Health Services Research (July 1, 1991).

${ }^{85}$ See Theodore R. Marmor, American Health Politics 1970 to the Present: Some Comments, Q. REV. ECON. \& BUS., Winter 1990, at 32, 32-34. 
ling health expenditures. Canada's and Britain's systems are most often cited, but most of Western Europe's achievements are comparable. ${ }^{86}$ In each case, the inherently inflationary forces in medical care that Robert Evans has so eloquently describedtechnological growth, asymmetry of information, uncertainty of evidence, and rising expectations-have been met with policy responses to counter powerful pressures for more spending. In Canada, that has meant the concentration of financial authority in single provincial payors, the use of global hospital budgets, the separate control of capital expenditures by hospitals, and the active setting of prices for physician services. In the United States, reforms failed to address those forces in a concerted fashion, and inflation has continued unabated. ${ }^{87}$

There are indications that America is moving toward universal health insurance. Recent public opinion polls show that a majority of Americans favor a national health insurance system over our present arrangements. ${ }^{88}$ The appearance in the elite New England Journal of Medicine of an editorial ${ }^{89}$ and an article ${ }^{90}$ supporting some form of universal health insurance signalled that the academic wing of the medical profession is ready to consider fundamental changes in the way that medical care is financed. An entire recent issue of the Journal of the American Medical Association extolled the virtues of universal access, ${ }^{91}$ suggesting that others will not be far behind. Congress appears prepared to consider such a program seriously for the first time in twenty years. ${ }^{92}$

${ }^{86}$ See A.J. Culyer, Cost Containment in Europe, in ORGANISATION FOR ECONOMIC Co-operation and Development, Health Care Systems in Transition: The SEARCH FOR EFFICIENCY 29, 30 (1990).

${ }^{87}$ An excellent technical account of these issues can be found in ROBERT G. Evans, STRAINEd MERCY: THE ECONOMICS OF CANAdian HEALTH CARE (1984). For a more general introduction to the same material, see Theodore R. Marmor \& Jerry Mashaw, Northern Light: Canada's Lessons for American Health Care, AM. PROSPECT, Fall 1990 , at 18.

88 See Robin Toner, Bad News for Bush as Poll Shows National Gloom, N.Y. TIMES, Jan. 28, 1992, at A1.

${ }^{89}$ See Arnold S. Relman, Universal Health Insurance: Its Time Has Come, 320 NEW ENG. J. MED. 117 (1989).

90 See David U. Himmelstein et al., A National Health Program for the United States, 320 NEW ENG. J. MED. 102 (1989). (1991).

${ }^{91}$ See Special Issue, Caring for the Uninsured and Underinsured, 265 JAMA 2491

92 See Theodore R. Marmor, U.S. Medical-Care System: Why Not the Worst?, WALL ST. J., June 20, 1991, at A15; Theodore R. Marmor et al., Political Handcuffs Hobble Debate, L.A. TIMES, Oct. 3, 1991, at B7. 
Still, most of these powerful parties are unconvinced that reform should include the kind of concentrated financial and regulatory power that has repeatedly proved successful abroad. In the context of the federal budget deficit and the public's hostility toward increased taxes, it is uncertain whether reform will follow the model of direct governmental financing. Some claim that a system that preserves the present employment-based insurance scheme and maintains some role for private insurance companies is politically more feasible. ${ }^{93}$ If such a program could be coupled with strong governmental regulatory powers, some observers believe that we might achieve universal access to medical care, while still containing costs. ${ }^{94}$

As the debate on major reforms heightens over the coming months, one truth will continue to be undeniable: contemporary medicine offers an astonishing array of beneficial therapies. These therapies will be sought by many patients wanting to improve their lives. They will be employed by doctors wanting to help their patients, exercise their craft, and earn their income. There is little hope that either of the intimate partners in the doctor-patient relationship will come to see most medical treatment as "wasteful."

Meanwhile, the "professional imperative" will prevail unless powerfully constrained. While many physicians will refrain from performing procedures known to be ineffective, most will not be willing to unilaterally cut other "wasteful" activities (practices of uncertain effectiveness, activities that are ethically problematic, and therapies that are not allocationally efficient). If doctors will not say 'no' to their patients, then we can expect that payers will begin to say 'no' to doctors. And indeed they have begun to do so. A new coalition has promised to cut health expenditures by making rules forbidding wasteful treatment. But it is doubtful that "cutting waste" is as straightforward or as painless as the most voluble members of the coalition have suggested. And it is certain that cutting waste by making rules will mean different things to different people.

93 See Henry J. Aaron, Serious and Unstable Condition: Financing AMERICA's HEALTH CARR 130-31 (1991).

${ }^{94}$ See id. at 124-28; Marmor \& Mashaw, supra note 87, at 18-29; Ronald Pollack \& Phyllis Torda, The Pragmatic Road Toward National Health Insurance, AM. PROSPECT, Summer 1991, at 92, 95; Paul Starr, The Middle Class and National Health Reform, AM. PROSPECT, Summer 1991, at 7, 11-12. But see Joe White, Why Congress Should Push a National Health Plan, WASH. POST, Sept. 15, 1991, at C3 (arguing that a Canadianstyle plan is more efficient and politically feasible). 


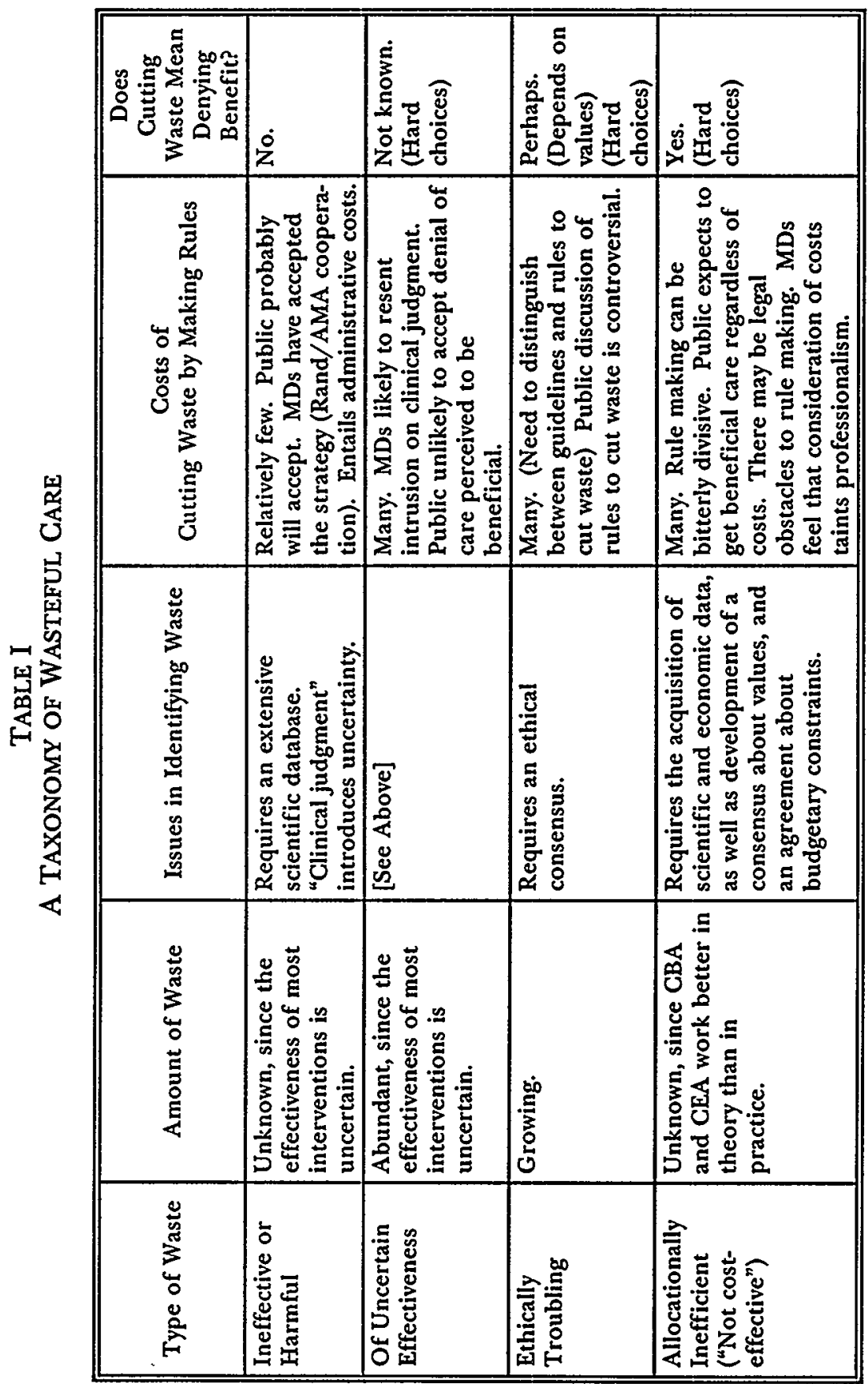


FIGURE I

A Plan for Medical Care Cost Containment

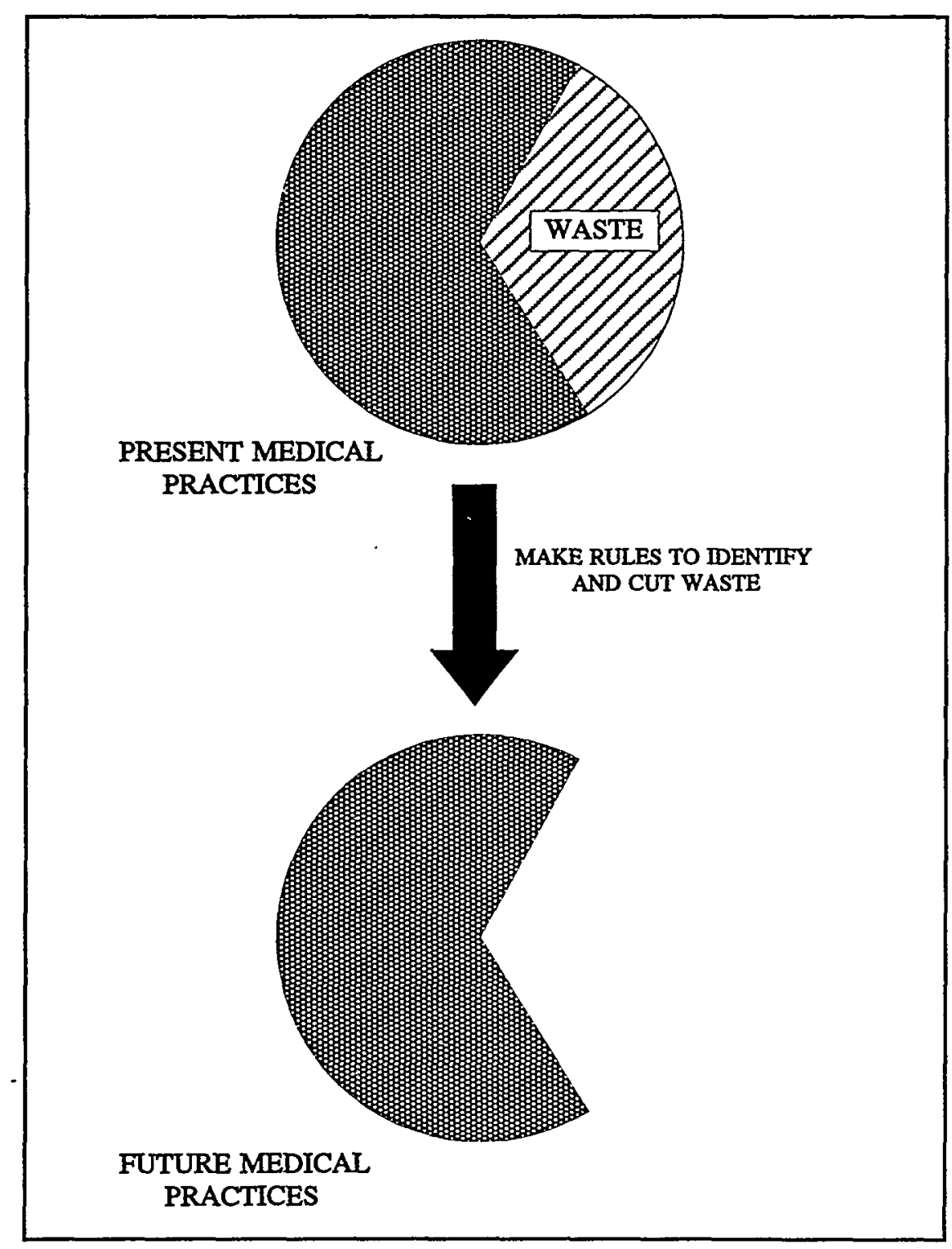




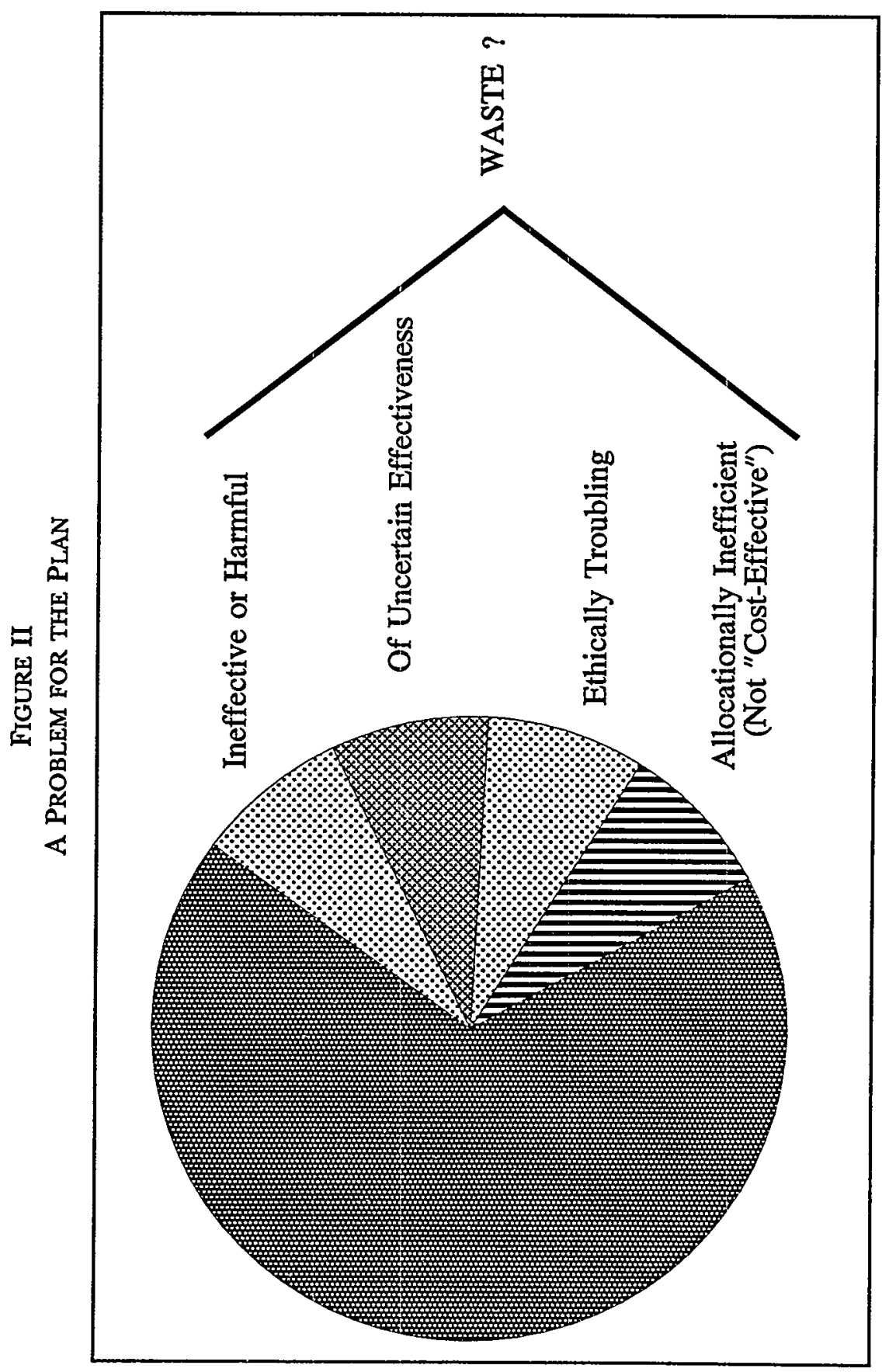

